\title{
Aerodynamic Performance and Turbulence Measurements in a Turbine Vane Cascade
}

Robert J. Boyle and Barbara L. Lucci

Glenn Research Center, Cleveland, Ohio

Richard G. Senyitko

QSS Group, Inc., Cleveland, Ohio 


\section{Acknowledgments}

The authors wish to acknowledge the helpful discussions with Dr. David Davis and Dr. Lennart Hultgren regarding the hot wire measurements.

The Aerospace Propulsion and Power Program at NASA Glenn Research Center sponsored this work.

Available from

NASA Center for Aerospace Information

National Technical Information Service

7121 Standard Drive

5285 Port Royal Road

Hanover, MD 21076

Springfield, VA 22100

Available electronically at http://gltrs.grc.nasa.gov 


\title{
Aerodynamic Performance and Turbulence Measurements in a Turbine Vane Cascade
}

\author{
R.J. Boyle and Barbara L. Lucci \\ National Aeronautics and Space Administration \\ Glenn Research Center \\ Cleveland, Ohio 44135 \\ Robert.J.Boyle@grc.nasa.gov \\ Barbara.L.Lucci@grc.nasa.gov \\ R.G. Senyitko \\ QSS Group, Inc. \\ Cleveland, Ohio 44135 \\ Richard.G.Senyitko@grc.nasa.gov
}

\begin{abstract}
Turbine vane aerodynamics were measured in a three vane linear cascade. Surface pressures and blade row losses were obtained over a range of Reynolds and Mach numbers for three levels of turbulence. Comparisons are made with predictions using a quasi-3D Navier-Stokes analysis. Turbulence intensity measurements were made upstream and downstream of the vane. The purpose of the downstream measuremen ts was to deternine how the turbulence was affected hy the strong contraction through $75^{\circ}$ of turning.
\end{abstract}

\section{Nomenclature}

$\begin{array}{ll}A_{0}, A_{1} & - \text { Coefficients in Voltage-Re relationship } \\ C_{n} & - \text { Pressure coefficient, }\left(P_{t-1}-P\right) /\left(P_{t-1}-P_{2}\right) \\ C^{\prime} & - \text { Axial chord } \\ E & - \text { Fluctuating voltage } \\ d & - \text { Time a veraged voltage } \\ h_{n} & - \text { Wire dianeter } \\ l & - \text { Knudsen number } \\ M & - \text { Length scale } \\ n & - \text { Mach number } \\ N u & - \text { Exponent on Reynolds number } \\ R e & - \text { Reynolds number } \\ s & - \text { Surface distance } \\ s & - \text { Span } \\ T & - \text { Temperature } \\ T u & - \text { Turbulence intensity } \\ U & - \text { Velocity } \\ Y & - \text { Loss coefficient, }\left(P_{t-1}-P_{\mathrm{t}-2}\right) /\left(P_{\mathrm{t}-1}-P_{2}\right) \\ \gamma & - \text { Specific heat ratio } \\ \mu & - \text { Molecular viscosity } \\ \rho & - \text { Density }\end{array}$

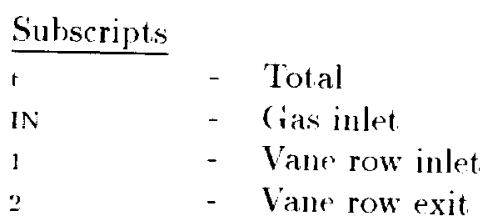

\section{INTRODUCTION}

There is an ongoing need to provide data for CFD analyses, and for information regarding flow behavior in turbomachinery blade rows. These data can be especially useful when they cover a range of Reynolds and Mach numbers, at different turbulence intensities. Actual turbines operate over a range in these parameters. Verification of the CFD analyses over a range of parameters increases confidence in the analyses. While the real interest in predictive analyses are for threedimensional flows, these analyses often use models determined from tests where the flows are primarily twodimensional in nature. If the phenomena of in terest is primarily two-dimensional, such as transition or profile loss, then tests where the flows are two-dimensional will most clearly illuminate their effects.

Vane aerodynamic performance has been reported by several researchers. As an example, Arts et al.[1] gave the total pressure distribution behind a vane in transonic flow. There is renewed interest in the aerodynamics of ceramic vanes because of their potential to reduce cooling requirements due to higher vane material temperatures. However, ceramic vanes need thicker trailing edges than do metallic vanes for the same chord length (Price et al.[2]). Aerodynamic efficiency depends on both the state of the boundary layer near the trailing edge, and the trailing edge thickness. Efficiency differences between laminar and turbulent suction surface boundary layers can be as great as those between thin and thick trailing edges. 


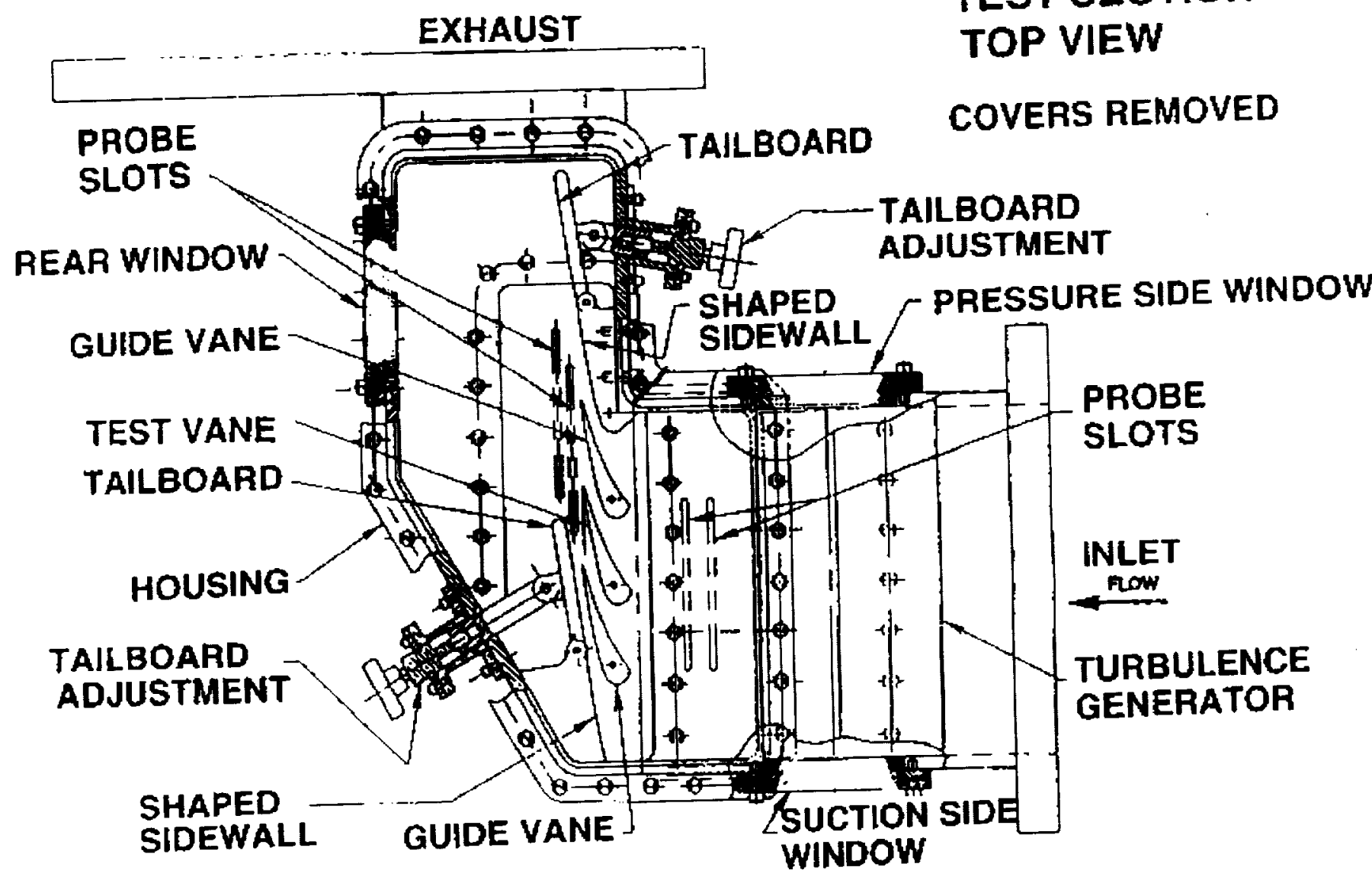

Fig. 1 Overall view of test section.

In small engine applications the Reynolds numbers are low, and the suction surface boundary layer could be laminar, even with a high inlet freestream turbulence. Since transition is dependent on the local turbulence intensity, it is important to know how the turbulence intensity varies with the acceleration through the vane passage. It was shown by Ames[3] that turbulence intensity was reduced considerably in passing through a vane cascade. His results were obtained at an exit Mach number of 0.27

The work presented herein gives surface pressures and aerodynamic performance of a turbine $v$ ane, with a shape suitable for ceramic engine applications. Results are given for a range of Reynolds and Mach numbers at different inlet turbulence intensities. Comparisons are made with a Navier-Stokes analysis to illustrate where improvements in the modeling are needed. Turbulence measurements made at the inlet and exit of the cascade are also discussed. The exit measurements were for Mach numbers into the high subsonic region. An approach to determining turbulence intensity in this flow regime is discussed. 


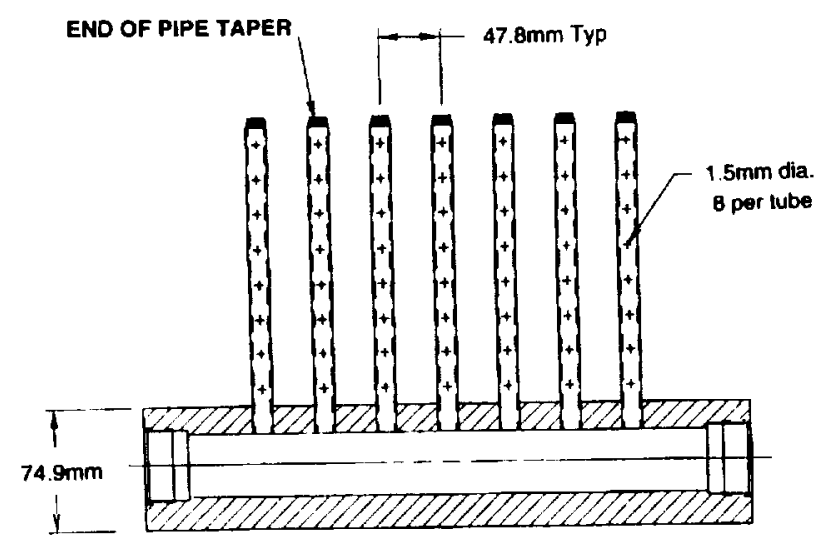

Fig. 2 Turbulence generator.

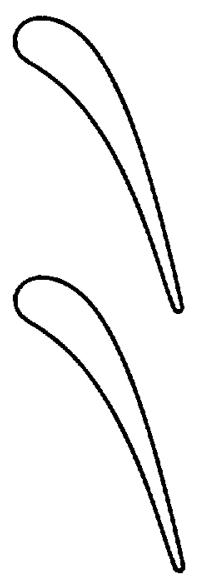

Fig. 3, Test vane and passage.

achieve the desired test section inlet pressure. The cascade exit connects to a low pressure, $(0.1 \mathrm{~atm}$.) altitude exhaust system. Inlet and exit valves are used to achieve the desired test conditions. Rows of upstream and downstream static taps on the cascade floor are used to calculate inlet and exit Mach numbers.

Figure 1 shows two slots 4.3 and $8.2 \mathrm{~cm}$ upstream and two slots 1.27 and $2.54 \mathrm{~cm}$ downstrean of the vanes. These slots extended approximately two vane pitches. They were used for inlet and exit surveys. Further details regarding the test facility and the approach taken to measure the surface pressures and exit surveys are given by Boyle et al.[4].

Data were ohtained for three inlet flow turbulence intensities. High turbulence levels were generated using two hlown grids $24.7 \mathrm{~cm}$ upstream of the vane leading edges. Figure 2 shows a grid consisting of seven spanwise tubes $1.59 \mathrm{~cm}$ in diameter. The $v$ ane leading edges were 15.5 diameters downstream of this grid. Air was blown upstream from the small. $1.5 \mathrm{~mm}$ holes in eac $\mathrm{h}$ tube. In previous work, Boyle et al.[4] it was found that blowing air counter to the main flow stream produced a more uniform pitchwise turbulence intensity than if no air was blown through the grid. Blowing air in the main flow direction resulted in greater non uniformities, than without air flow from the tubes.
Table I. Vane Characteristics

\begin{tabular}{|r|r|}
\hline Axial Chord. ( & $5.18 \mathrm{~cm}$ \\
True (hord & $10.40 \mathrm{~cm}$ \\
Pitch & $8.26 \mathrm{~cm}$ \\
Span & $21.59 \mathrm{~cm}$ \\
Trailing edge thickness & $0.26 \mathrm{~cm}$ \\
Flow turning angle & $75^{\circ}$ \\
\hline
\end{tabular}

The second turbulence generating grid differed from the one shown in figure 2 in the size and number of tubes. Eleven tubes. only $0.32 \mathrm{~cm}$ in diameter, were spaced $27.5 \mathrm{~mm}$ apart. When this gricl $w$ as used, the value leading adges were 78 diameters clownstream of the grid. Consecpuently, the turbulence intensity was expected to be lower with this grid. The scale of the turbulence was expected to be significanty smaller. Results for the large tube and small tube grids are referred to as large grid and small grid results respectively.

In addition to the cascade, a calibration nozzle rig was used. 'The calibration nozzle' was primarily used to calibrate hot wires. It could also be used to calibrate total pressure probes. The jet could deliver air at up to sonic velocity, at one atm. static pressure. The total temperature was the ambient temperature. The nozzle exit diameter was $3.8 \mathrm{~cm}$.

Figure 3 shows the test vane. This vane was chosen because of its relatively thick trailing edge-to-chord ratio. Table I gives several of the vane parameters. The coordinates of the test vane are given in Appendix $A$. This vane shape was chosen because it was suitable for a ceramic vane, since it had a appropriate trailing edge thickness. A vane of larger size and the same geometry was tested by Schwab[5]. He tested the vane in a low turbulence intensity linear cascade at one inlet total pressure. The aerodynamic performance $w$ as measured for exit Mach numbers in the high subsonic range. The tests showed high aerodynamic efficiency. The kinetic energy loss coefficient was 0.028 at an exit Marh number of 0.9 .

\section{DESCRIPTION of ANALYSIS}

Predictions of loss and surface pressures were done using the quasi-3D Navier-Stokes code RVCQ3D. This code has been documented by Chima[6] and by Chima and Yokota[7]. The code was run as a two-dinensional analysis. C-type grids were generated using the method of Arnone et al.[8]. In this approach, the near-wall grid is embedded within a coarser grid obtained using the method of Sorenson[9]. For this work dense grids were used. A typical grid was $257 \times 55$. The results presented by Boyle[10], and by Boyle and Ameri[11] were used to insure that the calculations were grid independent. The solutions were monitored to assure that convergence was achieved. The algebraic turbulence model, and the transition model described by Boyle and $\mathrm{Si}$ mon[12] were used. 


\begin{tabular}{|c|c|c|}
\hline$M_{2}$ & $\begin{array}{c}P_{1-1} \\
(\mathrm{a}(111)\end{array}$ & $\begin{array}{c}R C^{\prime} \\
\times 10^{-13}\end{array}$ \\
\hline 0.3 & 0.20 & 0.066 \\
& 1.4 & 0.461 \\
\hline 0.5 & 0.20 & 0.103 \\
& 1.4 & 0.718 \\
\hline 0.7 & 0.27 & 0.176 \\
& 1.2 & 0.781 \\
\hline 0.9 & 0.30 & 0.221 \\
& 1.2 & 0.886 \\
\hline
\end{tabular}

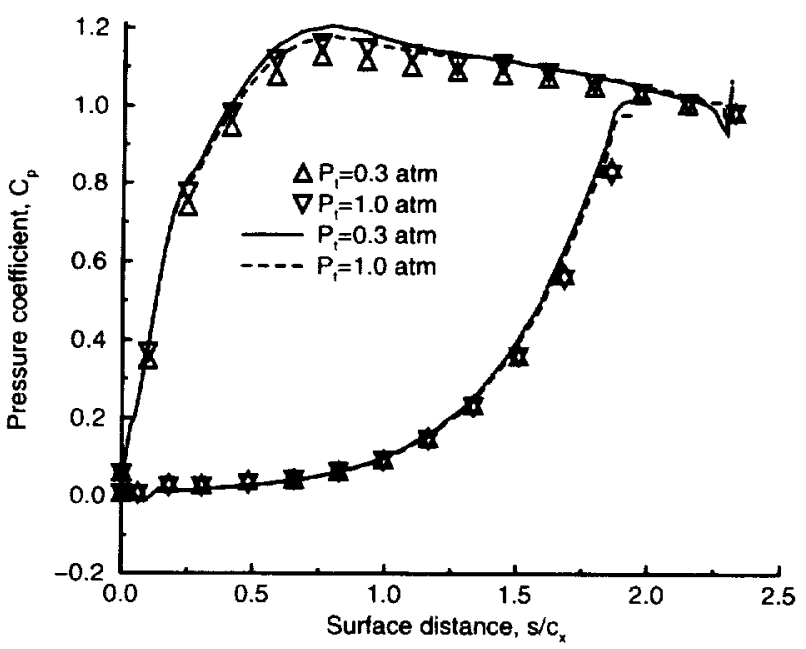

Fig. 4a Predicted and measured pressure coefficients, $M_{2}=0.3$

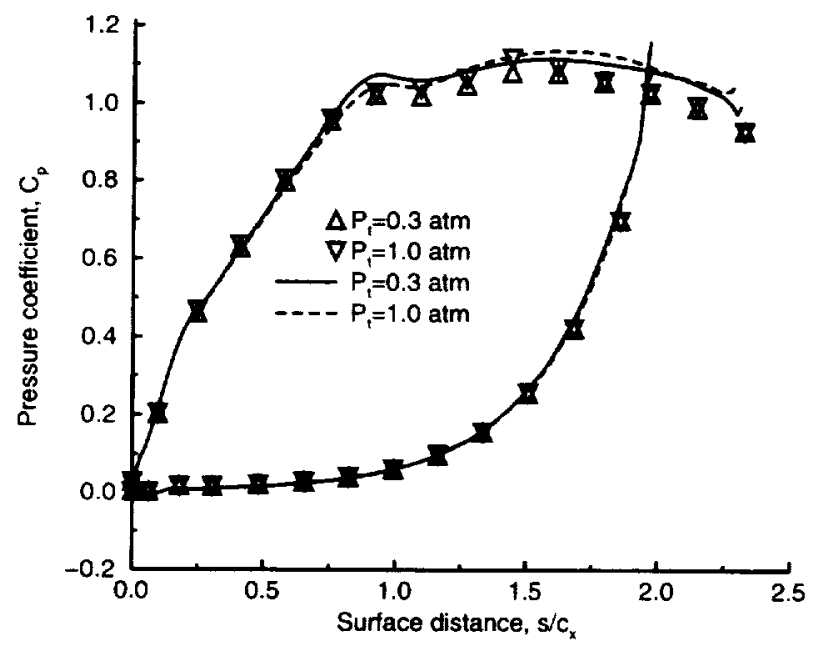

Fig. 4b Predicted and measured pressure coefficients, $M_{2}=0.9$

\section{DISCUSSION OF RESULTS}

Aerodynamic performance.

Table II lists the exit Mach numbers, and the range of inlet total pressures for which data were obtained. The axial chord Reynolds number at the cascade exit is also shown for the range of test conditions. The highest Reynolds number is more than ten times greater than the lowest one.

Figures 4a and 4h show pressure distributions for $M_{2}=0.3$, and 0.9 . Neither the measured nor predicted $C_{p}$ distributions show significant variations due to changes in inlet total pressure. The pressure distributions show very little suction surface diffusion,

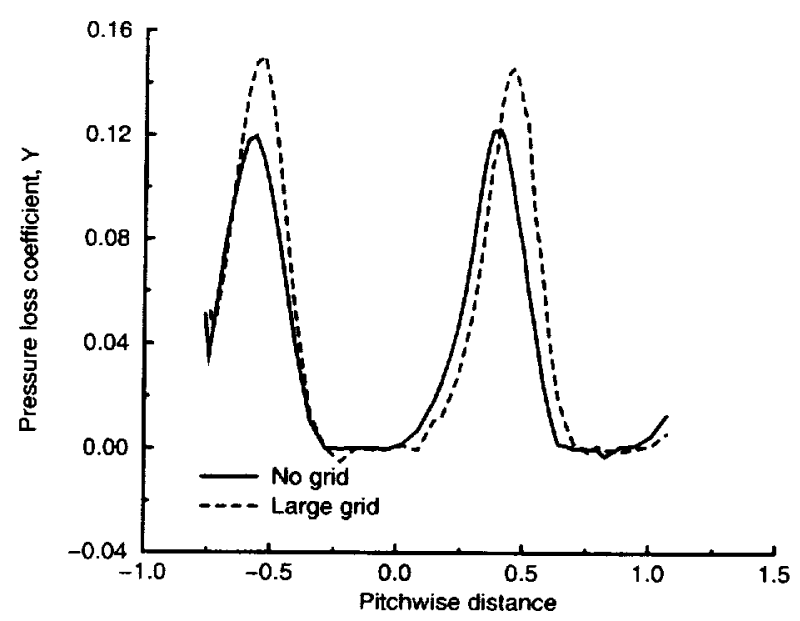

Fig. 5 Wake profile at $M_{2}=0.9, P_{1}=0.68$ atm.

indicating that the vane row losses should be low. Intermediate Mach number pressure coefficients were between those shown for the low and high Mach numbers.

Figure 5 shows the measured total exit pressure distributions for a no-grid case. and for the large grid with blowing air. The comparison is at the sante Reynolds and Mach numbers. There is a greater loss in the wake region for the large grid case. This is consistent with a thicker suction surface boundary layer. The earlier transition due to the higher turbulence level for the grid case leads to a thicker suction surface boundary layer. The slight shift in the location of peak loss between the high and low turbulence cases is due to a small change in the exit flow angle. The change in flow angle is attributable to a cliange in the boundary layer thickness.

Figure 6 shows average vane total pressure loss coefficients for three inlet turbulence intensities and four exit Mach numbers. There was significant uncertainties in loss at the lowest Mach number, (0.3), at low inlet total pressures, (Reynolds numbers). This was due to the difficulty in maintaining a constant inlet total pressure to a very tight tolerance during the entire total pressure survey. The survey took approximately 20 minutes, to allow the total pressure to stabilize at each pitchwise location. The stabilization time was needed because of very small diameter tubes in the seven hole exit survey probe compared to the larger tube in the inlet total pressure probe. At low Mach numbers these small changes in absolute pressure translated into large uncertainties in dynamic pressure. Even with the scatter. the data at $M_{2}=0.3$ are consistent with those at $M_{2}=0.5$

The low turbulence intensity, no grid cases, are all characterized by a high loss coefficient at low inlet pressures. At each Mach number, as the inlet pressure, and, therefore, Reynolds number, increases, the loss decreases to a minim um value. The initial decrease in loss is expected, since the friction factor decreases as Reynolds number increases. This is followed by increased loss. After the region of minimum loss, the 


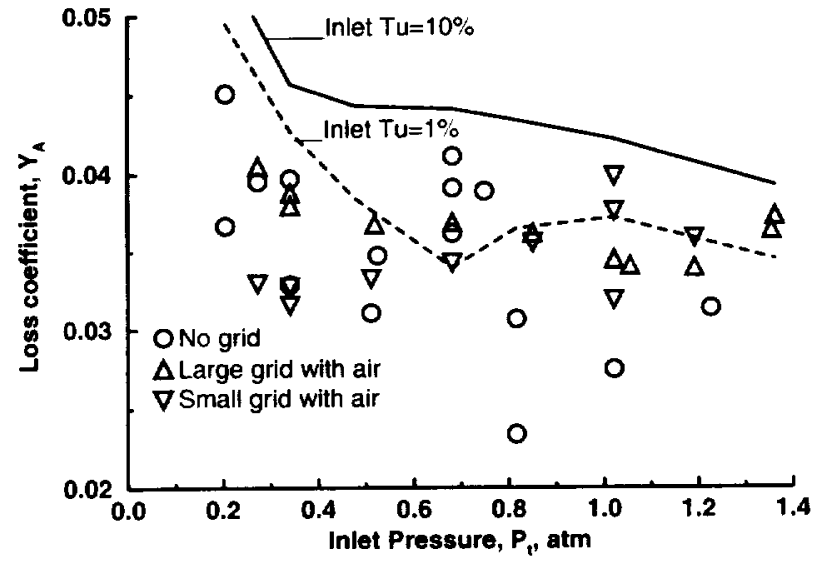

Fig. 6a Predicted and measured loss coefficient at exit $M_{2}=0.3$

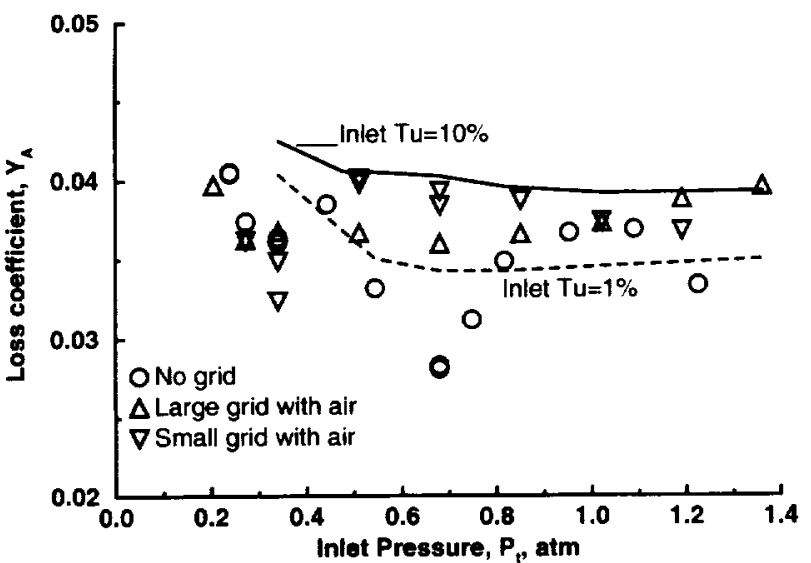

Fig. 6b Predicted and measured loss coefficient at exit $M_{2}=0.5$

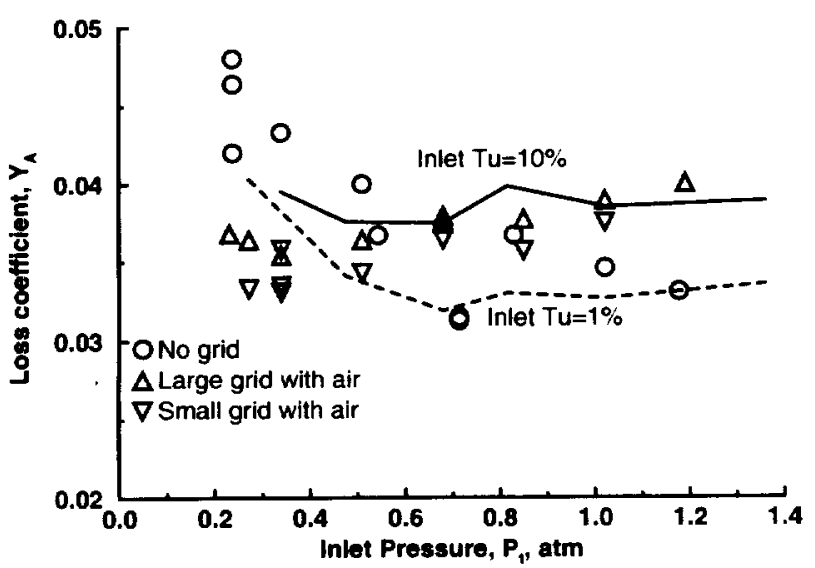

Fig. 6 c Predicted and Measured loss coefficient at exit $M_{2}=0.7$

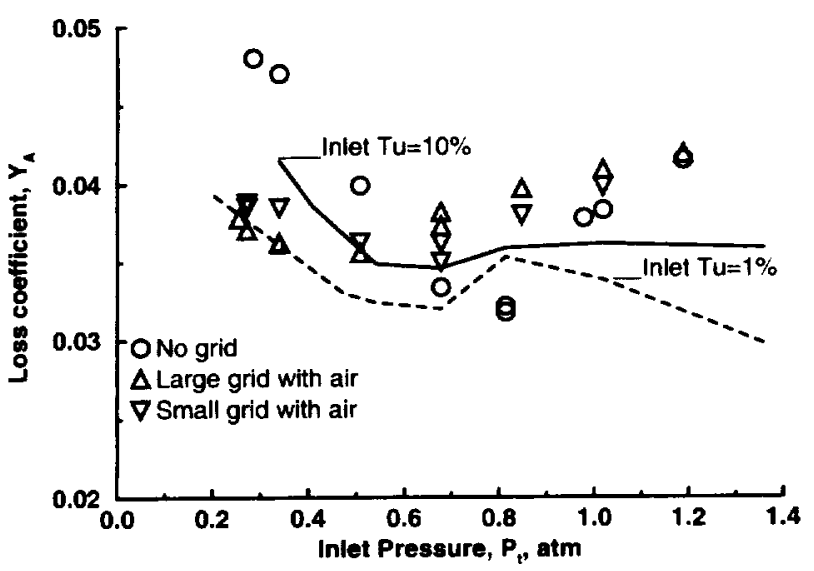

Fig. 6d Predicted and measured loss coefficient at exit $M_{2}=0.9$
Table III. Wire Reynolds and kin udsen numbers

\begin{tabular}{|r|c|c|c|}
\hline $\begin{array}{r}P^{\prime} \\
\text { (atm) }\end{array}$ & $M$ & $R^{\prime}, 1$ & $K \eta$ \\
\hline 0.333 & 0.3 & 8 & 0.055 \\
0.667 & 0.3 & 16 & 0.027 \\
1.0 & 0.3 & 24 & 0.018 \\
\hline 0.333 & 0.7 & 15 & 0.069 \\
0.667 & 0.7 & 30 & 0.0134 \\
1.0 & 0.7 & 45 & 0.023 \\
\hline 0.333 & 0.9 & 16 & 0.082 \\
0.667 & 0.9 & 33 & 0.041 \\
1.0 & 0.9 & 49 & 0.027 \\
\hline
\end{tabular}

suction surface is probably unclergoing transition from laminar to turbulent flow. At Mach mumbers of 0.5 and 0.7 . the measurements show a slight decrease in loss with increasing Reynolds number, as is expected for fully turbulent flow. However, at the highest Mach number. 0.9. there is a contimuing loss increase at high pressures. The experimental data in figure 4 b shows a slight increase in suction surface diffusion as pressure increases. This may account for the higher loss at the highest pressure.

For the large grid, and therefore highest turbulence intensity, loss is fairly constant with respect to inlet pressure at all four Mach numbers. This indicates that the suction surface boundary layer was turbulent at the trailing edge for all cases with high turbulence. It will be shown later that the small grid with blowing gave inlet turbulence intensities about half that of the large grid with blowing. The sntall grid result show interesting results. Figures $6 \mathrm{c}$ and $6 \mathrm{~d}$ show that at low pressures, (Reynolds numbers), the loss for the intermediate turbulence level is close to that for the high turbulence level. The losses are significantly lower than that for the low turbulence, no grid, cases. However, at higher pressures the intermediate turbulence losses are generally between losses for low and high turbulence.

The high turbulence intensity analysis was done with an inlet turbulence intensity of $10 \%$. This was done to approximate the turbulence intensity at the vane leading edge. The analytic results are shown to give predictions with a relatively simple turbulence model. It is expected that improved turbulence models will show better agreement with data. Overall, the analysis and experimental data agree fairly well. At both turbulence intensities the analysis shows increased loss at low Reynolds numbers as the inlet pressure is decreased. Figures $6 \mathrm{a}$ and $6 \mathrm{~b}$ show that in this region the analysis overpredicts losses. At low inlet turbulence the analysis overpredicts losses in the region of minim um loss. This is clearly seen near an inlet pressure of $0.6-0.8$ at.m. in figures $6 \mathrm{a}$ and $6 \mathrm{~b}$.

\section{Hot wire measuremen ts.}

Tests were done in the calibration jet to determine the appropriate probe configuration for the cascade measurements. To maxim ize frequency response all probes used a 3.8 micrometer diameter tungsten wire. An objective of the hot wire measurements was to determine the turbulence intensity at high subsonic 
Mach numbers. This was done using single wire proles ('are was taken to insure that the measurements reflected only flow turbulence, and not probe vibrations. To resolve the turbulence in the wake a TSI model 1211 was considered. This probe has the wire axis aligned in the spanwise direction, and would give the best pitehwise resolution. 'The spectrum analysis of the probe showed large voltage spikes at higher Mach numbers in the frequency range between 5 and $20 \mathrm{kHz}$. The magnitude of the spikes increased as the Mach numher increased. Other probes, which did not have as good pitchwise spacial resolution, were lested in the calibration jet. Model 1210 and 1212 probes were tested. These probes have the hot wire axis normal to the spanwise diecetion. At the vane exit, the wire is made perpendicular to the main flow direction by rotating the probe. A model 1213 probe, which has the hot wire at $45^{\circ}$ to the span, was also tested. These tests showed that the model 1212 probe had the hest frequency response at high Mach numbers. This type probe was used for the vane exit measurements. At the highest Mach number of 0.9 . excessive wire breakage was atso observed for the 1211 and 1210 model probes. As suggested by Dr. David Davis, using a non-conductive epoxy to bridge the prongs reduced breakage. But, the frecuency response was not improved. At the low Mach numbers seen at the inlet, there was little difference in the measured turbulence intensity between probe types. $A$ model 1211 probe was used for the inlet turbulence measurements. Measuremen ts made in the calibration jet were consistent with those seen in the test rig, even at lower pressures.

Measuremen ts of the turbulence intensity were made both upstream and downstream of the cascade for a range of pressure ratios. The signals were processed using a Dantec 90-10 controller. The downstream measurcments were for pressure ratios corresponding to Mach numbers from 0.3 to 0.9 . The primary concern with regard to the exit measurements was that they accurately measured the turbulence intensity over the range of exit conditions. The highest Reynolds number test condition was about one atmosphere at an exit Mach number of 0.9. At ambient temperature this results in a wire Reynolds number of 50 . The combination of low Reynolds and high Mach numbers gives relatively high Knudsen numbers $(\Lambda)=1.49 M / R c)$. Table III gives wire Reynolds numbers for different rig operating ronditions. Following Behrens[13], the wire Reynolds number is based on local density and the viscosity at the stagnation temperature. A stagnation temperature of $300 \mathrm{~K}$ was used. The hinudsen numbers ranged between $0.01<K n<0.1$. There is a Knudsen number effect of the heat transfer for $K n>0.001$, (Sandborn[14]) In the flow regime of the present tests wire Nusselt number is a function of both the Reynolds and Mach Numbers. At constant Reynolds number the Nusselt number decreases with increasing Mach number.

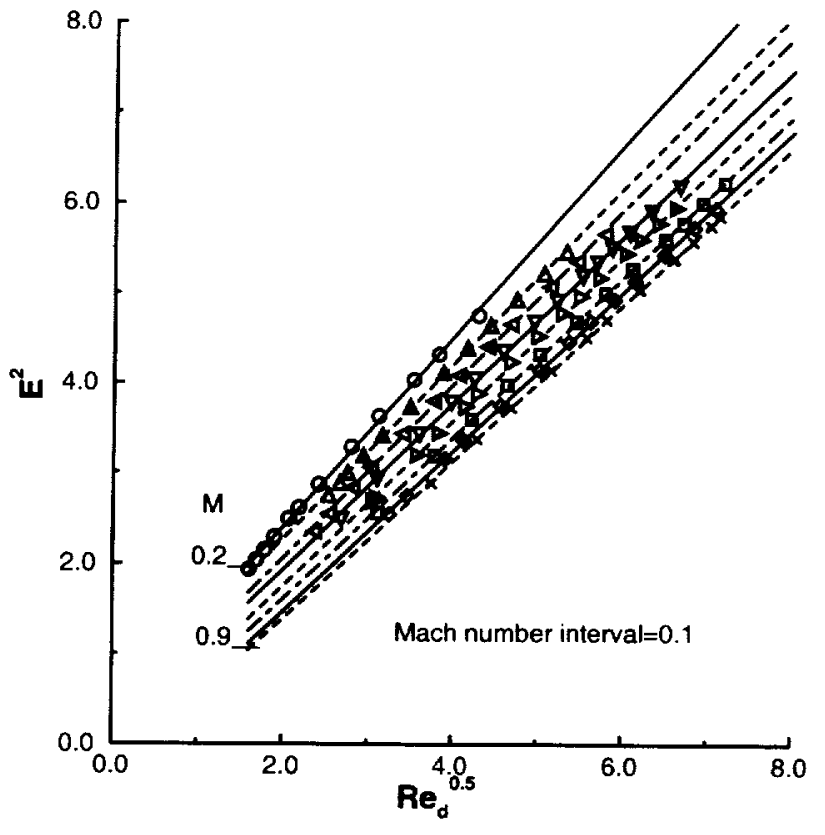

Fig. 7 Calibration curve for a typical hot wire.

The recovery temperature increases with hinudsen number, and can exceed the gas total temperature. This is significant from the standpoint the hot wire response.

At high Mach numbers the hot wire fluctuating voltage, $\epsilon^{\prime}$ responds to fluctuations in velocity, density, and temperature. To estimate the coefficien ts for ead variahle, multiple overheat values can he used.(Bruun[15]). However, several overheat values are needed to assure reasonable accuracy. An alternate approach, suggested by Barre et al.[16], is to use a single high overheat ratio. Then relationships between the velocity, density, and temperature fluctuations are assumed. This alternate approach was used for the work presented. A linear relationship was found to accurately represent the change in voltage with Reynolds number at constant Mach number.

$$
E^{2}=A_{0}+A_{1} R \epsilon_{d}^{\pi}
$$

Figure 7 illustrates that this relationship was strongly dependent on the Mach number. Variations in Reynolds number at constant Mach number were achieved by varying the inlet total pressure while maintaining the same pressure ratio across the cascade. The calibration plot shown in this figure is typical of that seen for all probes tested. This figure shows that $n=0.5$ and a linear fit to the data gives an accurate fit to the data. While, $n=0.45$ gave a slightly lower deviation in the curve fits, as suggested by Bruun[15], there was no significant improvement in doing so. The second observation is that because the calibration lines are almost parallel, the voltage for zero Reynolds number varies with Mach number. The curve fits often gave negative values for the voltage at zero flow, $\left(A_{0}<0\right)$. 


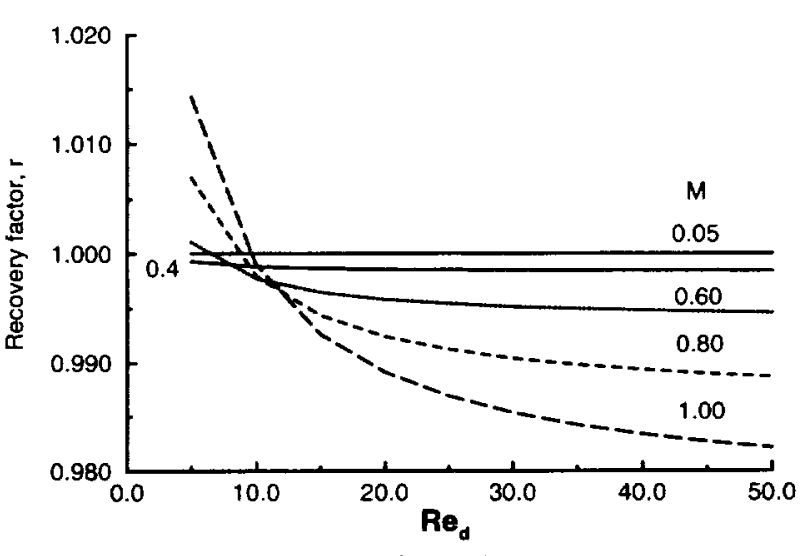

Fig. 8 Recovery factor in the slip flow regime.

Negative values were seen for high Mach numbers, and for values of $n<0.5$. This means that the linear fit does not apply for Reynolds numbers lower than the data points. This is significant when a modified version of ling's law is used to determine the turbulence in tensity. The modified equation is:

$$
T u=\frac{0.5 r^{\prime} E}{n\left(E^{2}-A_{0}\right)}
$$

If $A_{0}$ is a negative value derived from the curve fit, the turbulence intensity is underestimated. When $A_{0}$ is replaced by the no-flow hot wire voltage, $E^{2}\left(R \epsilon_{d}=0\right)$ a significantly higher turbulence intensity is calculated. Using the no-flow voltage gave turbulence intensities up) to $50 \%$ greater than using the curve fit values.

Figure 7 shows that the slope of $E^{2}$ versus $\sqrt{R \epsilon_{d}}$ at constant $\mathbf{M}$, is positive. But, the change in $E^{2}$ with $M$ at constant $R \epsilon_{d}$ is negative. Since $\rho^{\prime} u^{\prime} \propto R \epsilon_{d}^{\prime}$, it is necessary to develop a relationship between $R \epsilon_{\mathrm{d}}$ and $\epsilon^{\prime}$, (the rms voltage). If, instead of using the rms voltage, the instantaneous voltages are used to determine $R \epsilon_{d}^{\prime}$, the problem is equivalent. The instantaneous $R \epsilon_{\mathrm{r}}$ values have to be determined from the instantaneous voltage, and the knowledge of some other parameter at that instant, such as the Mach number.

The rms voltage is always positive, even if the fluctuating velocities are negative. The square of the rms voltage is related to the fluctuating Reynolds number and recovery temperature by.

$\epsilon^{\prime 2}=\left(\frac{d E}{d R \epsilon_{\mathrm{d}}}\right)^{2} \bar{R} \epsilon^{\prime 2}+2 \frac{d E}{d R \epsilon_{\mathrm{d}}} \frac{d E}{d T_{\mathrm{r}}} \bar{R} \epsilon^{\prime} \bar{T}_{\mathrm{r}}^{\prime}+\left(\frac{d E}{d T_{\mathrm{r}}}\right)^{2}{\overline{T_{\mathrm{r}}}}^{2}$

Since the recovery temperature fluctuations, $T_{r}^{\prime}$, are only weakly dependent on the Mach number, the second and third terms in the above equation are neglected.

If the term $d E / d R \epsilon_{\mathrm{d}}$ is taken as:

$$
\frac{d E}{d R \epsilon_{\mathrm{d}}}=\left.\frac{\partial E}{\partial R \epsilon_{\mathrm{d}}}\right|_{M}+\left.\frac{\partial E}{\partial M} \frac{M}{R_{\mathrm{d}}}\right|_{\mathrm{Re}_{\mathrm{e}}}
$$

the Knudsen number dependency becomes explicit, since $M / R e_{d}=0.67 \mathrm{~h} n$. At low hudsen numbers,

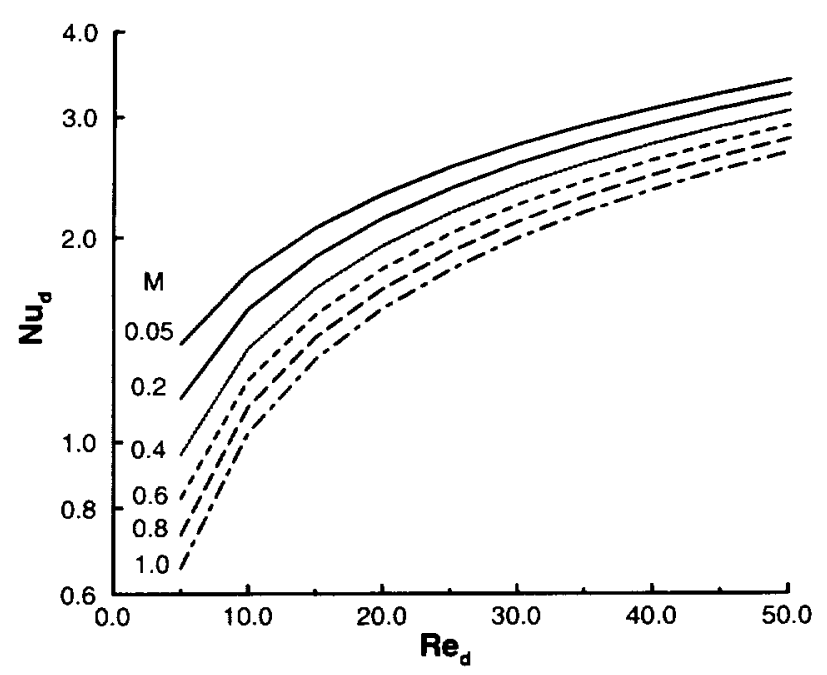

Fig. 9 Nusselt number in the slip flow regime.

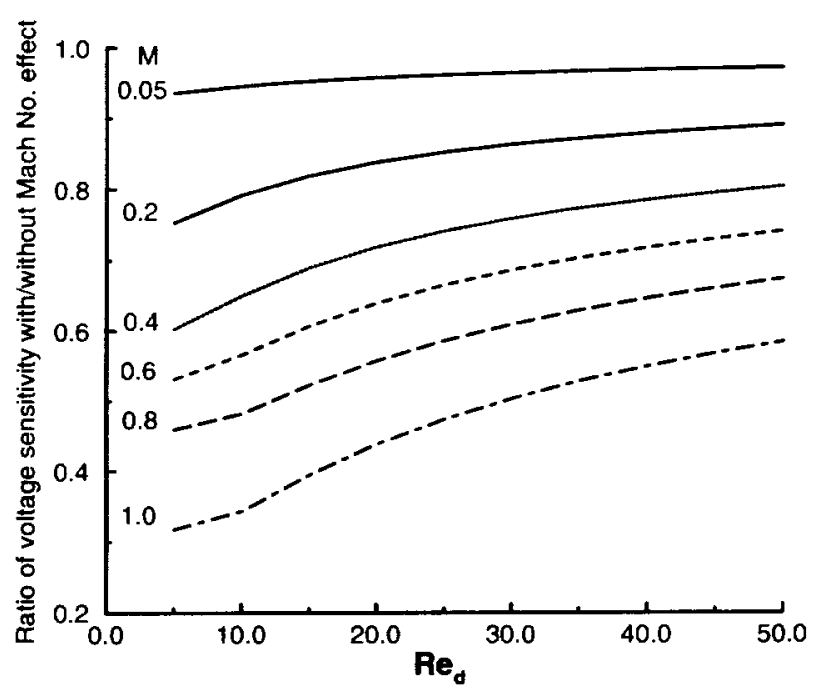

Fig. 10 Effect of Mach number on Reynolds number sensitivity.

the second term becomes negligible. Taking the derivative directly from the plot shown in figure 7 overestinates the effect of Mach number variation at constant Reynolds number. At high Knudsen numbers the second term can he as large as the first term, and is opposite in sign. A near zero value for $d E / d R \epsilon_{\mathrm{d}}$ leads to extremely large $T u$ values even when $f^{\prime}$ is very small. The overestimation occurs because increasing the Mac $h$ number at constant. Reynolds number also changes the temperature difference $T_{w}-T_{\mathrm{r}}$. Figure 8 shows the variation in adiabatic wall temperature ratio as given by Behrens[13]. For Mach numbers below 0.4, the temperature ratio is virtually unity. However. for $M=1$, and low Reynolds numbers the adiabatic wall temperature exceeds the total temperature. As the Reynolds number increases, the temperature ratio approaches the value of 0.975 . The value of 0.975 , corresponds to the continuun flow value with a recovery factor of 0.85 . While the $v$ ariation in temperature ratio appears to be small, at high Mach numbers the output voltage can be significantly affected.

The second term was evaluated by taking the derivative as: 


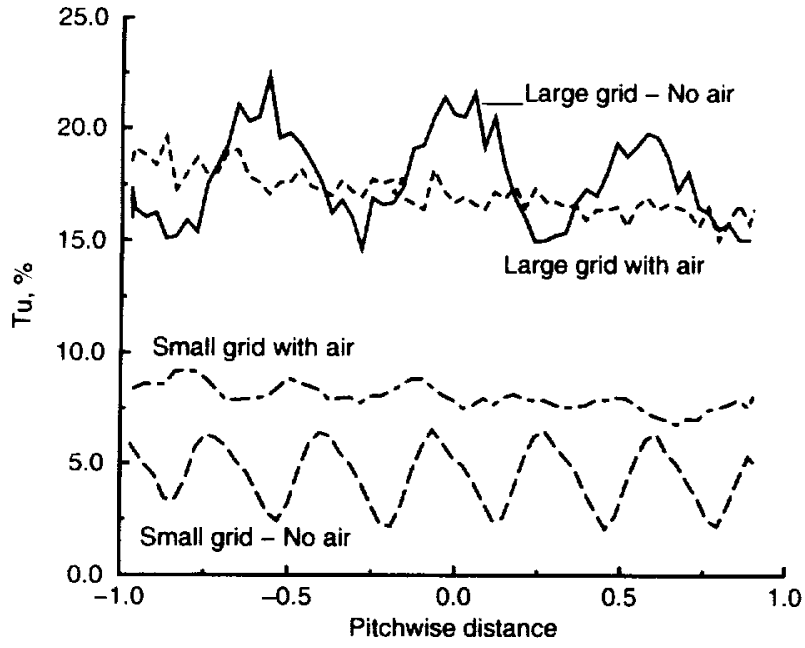

Fig. 11 Turbulence intensity upstream of vane row.

$$
\frac{\partial E}{\partial M}=\frac{\partial E}{\partial N u_{d}} \frac{\partial N u_{\mathrm{d}}}{\partial M}
$$

The term $\partial N u_{d} / \partial M$ was evaluated using the results presented by Behrens(1971) for the variation of Nusselt number with Reynolds and Mach numbers in the slip flow regime. Figure 9 shows that the decrease in Nusselt number with $\mathrm{Mach}$ number remains relatively constant over the Rrynolds number range.

Since $E^{2}$ is proportional to the heat transfer coefficient, $\partial E / \partial N u_{\text {d }}=E / 2 N u_{\mathrm{d}}$. Figure 10 shows the effect of including the Mach number variation in terms of determining the response of the wire to Reynolds number fluctuations. This is not a general curve, since it uses only the response of a representative wire. Other calibration curves show similar Mach number effects. At the lowest test condition shown in Table II for a $\mathrm{Mach}$ number of 0.9 the voltage sensitivity with the Mach number effect is only about half the sensitivity when the Mach number effect is neglected. Consequently, including the Mach number effect almost doubles the turbulence intensity. When no Mach number correction was used, calibration jet results showed decreasing turbulence intensity as Mach number increased. The calibration jet, having a one atmosphere static pressure, had $R t_{d}$ values at high Mach numbers greater than the test rig.

The rms value for the fluctuating Reynolds number, $R \epsilon_{d}^{\prime}$, is found from:

$$
R \epsilon_{\mathrm{d}}^{\prime}=\frac{r^{\prime}}{d E / d R e_{\mathrm{d}}}
$$

The remaining task is to determine the fluctuating velocity, $u^{\prime}$, from the fluctuating Reynolds number. The fractional fluctuations for $\rho u$ are the same as those for the Reynolds number, since:

$$
\frac{\rho^{\prime} u^{\prime}}{\bar{\rho} l}=\frac{R \epsilon_{d}^{\prime}}{R \epsilon_{d}}
$$

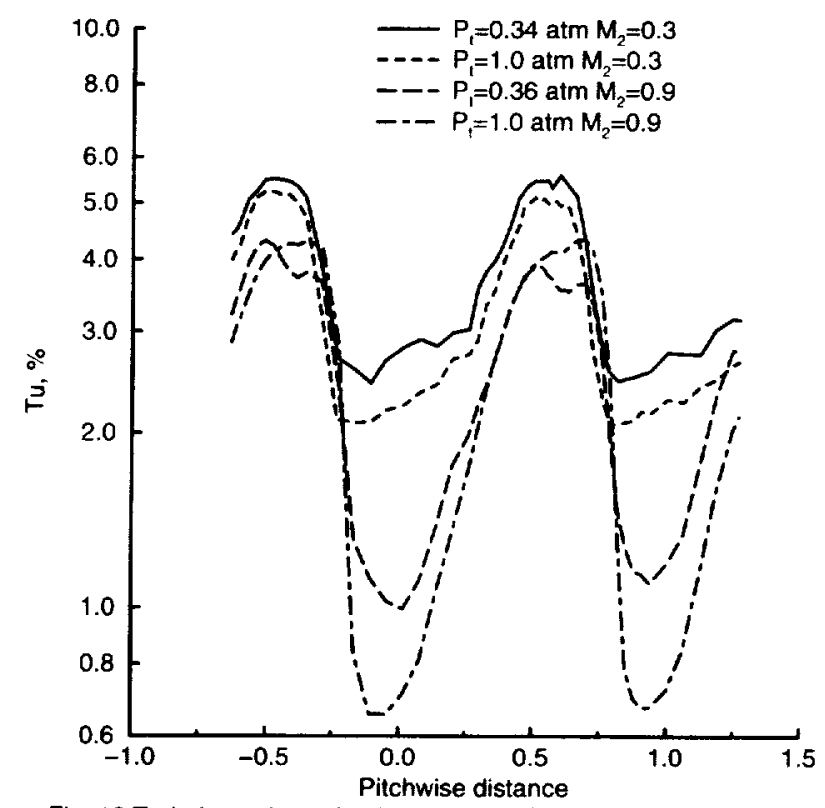

Fig. 12 Turbulence intensity downstream of vane row.

To compare turbulence intensities at different Mach numbers Markovin[17] corrected the Reynolds number His correction was a function of $M^{2}$, and reduced the turbulence by $25 \%$ at $M=0.9$. However, Horstman and Rose[18] claimed that the velocity sensitivity was the same mass flow sensitivity, and:

$$
T u=\frac{u^{\prime}}{\ell !}=\frac{\rho^{\prime} u^{\prime}}{\bar{\rho} I}=\frac{R \epsilon_{d}^{\prime}}{R r_{d}}
$$

Because the Mach number correction is incorporated into the Reynolds number sensitivity, the approach advocated by Horstman and Rose was adopted.

Upstream measuremen ts. Figure 11 shows the turbulence intensity upstream of the cascade. The measurements are at the midspan plane. Traverses were made at different spanwise locations. When grid air $w$ as not used there was, as expected. no variation of turbulence intensity with span. Even when grid air was used, there was no turbulence intensity variation with span. This is believed to be due to the high pressure inside the tubes. This pressure of nearly 10 atm. allows the grid air to penetrate far upstream, and thus mix well with the mainstream air. With grid air there is only a small pitchwise variation with span. However, even for the grid with the snall diameter tubes, there is a noticeable pitchwise variation in turbulence intensity.

Downstream measuremen ts. All results are shown for the large grid with blown air in the tubes. The large tube grid provided the highest level of inlet turbulence. Measuremen ts with the large grid installed indicate how strongly the turbulence intensity is modified as the flow passes through the vane passage. The turbulence intensity, both upstream and downstream, were calculated using the no-flow voltage for $A_{0}$. This maxim izes the 


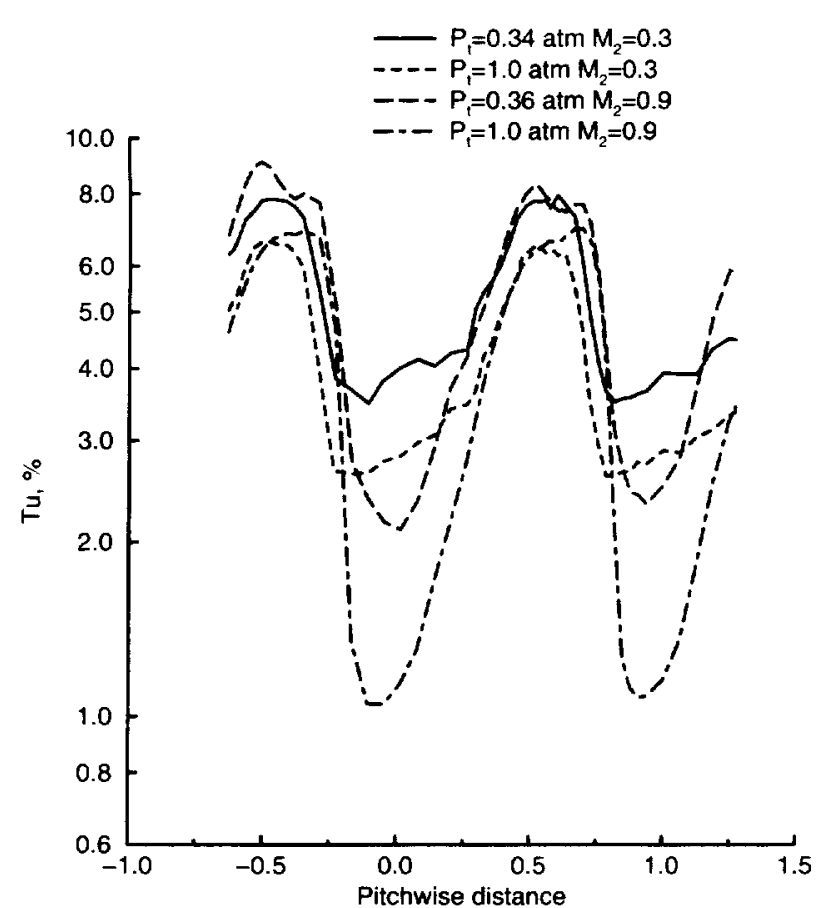

Fig. 13 Corrected turbulence intensity.

local turbulence intensity. For some cases the the turbulence intensity is nearly a third greater than it would be if the curve fit value for $A_{0}$ was used. For all test conditions the flow exit angle was approximately $75^{\circ}$. For $M_{2}$ less than about 0.3 , the ratio of exit to inlet total velocity is 3.73. At higher exit Mach numbers the ratio is greater. For an exit Mach number of 0.9 the ratio of exit-to-inlet total velocity is 5.43. But, even at $M_{2}=0.9$, the $\rho l$ product, which the hot wire responds to is still 3.73. In either case. the exit turbulence intensity is expected to be significantly less than the iniet value. Steelant and Dick[19] postulated that the turbulence intensity ratio varies as the velocity ratio to the three-halves power.

$$
\frac{T u_{2}}{T u_{1}}=\left(\frac{L_{1}}{T_{2}}\right)^{3 / 2}
$$

For a velocity ratio of 3.7 the Steelant and Dick turhulence intensity correlation gives a factor of 7.1 reduction in turbulence intensity between the inlet and exit of the vane row. Boyle and Simon[12] assumed that the fluctuating velocity remained constant, so that the exponent would be one. With this assumption the turbulence would decrease by less than a factor of four.

The results in figure 12 have no Mach number correction to the voltage sensitivity. The first observation is that the downstream measuremen ts at $M_{2}=0.3$ are consistent with the correlation of Steelant and Dick. The minim um turbulence in tensity is near pitchwise locations of zero and one. These are the locations for the freestrean. The data at $M=0.3$ and at a pressure of one atmosphere are the most appropriate for comparison with models for the variation of turbulence with velocity. The turbulence intensity between the wakes is just over $2 \%$. The inlet turbulence intensity was nearly $16 \%$. If the curve fit intercept was used, the downstream turbulence intensity would be less. This in turn would strengthen the argument in favor of the Steelant and Dick correlation. Ising the correlation intercept causes the turbulence intensity at a lower pressure to be reduced more than the turbulence intensity at a higher pressure. The correlation intercept for $f_{0}$ causes both curves for $M=0.3$ to have about the same values. The one atmosphere curve changes little from that shown in figure 12. The second observation is that the higher Mach number results show a lower turbulence intensity. Since these results are for higher kinudsen numbers. the sensitivity of turbulence intensity to voltage is greater.

The wakes shown in figure 12 at pitchwise locations of -0.5 and 0.5 nearly double that of the freestream. Measurement ts were made in the downstream slot further away from the trailing edge. The turbulence intensity has a rounded peak. In addition to turbulence decay, the hot wire may not have heen able to sufficiently spatially resolve the measurements. The wire was perpendicular, not parallel to the trailing edge.

Figure 13 shows the effects of including the slip flow Mach number correction given in figure 10. Midpassage turhulence intensity at $M_{2}=0.9$ are now closer to those at $M_{2}=0.3$. At $M=0.9$ the turbulence intensity increased by more that a factor of two for the low pressure case. The one atmosphere case increased by nearly a third. These results are consistent with those of Barre e1 al.[15]. They indicated a $50 \%$ increase in turbulence intensity after accominting for Mach number effects are. If Markovin's approach to account for Madı number effects had been used, the results in figure 13 would be similar to those in figure 12 . Mark ovin's Mad number correction would, to a large extent, cancel the Mach number correction from figure 10 . Figure 12 shows a lower wake turbulence intensity for $M_{2}=0.9$ than for $M_{2}=0.3$. However, the percentage differences are not as great as for the midpassage. After the Mach number correction, figure 13 shows little difference in the wake region between the two Mach number results.

\section{CONCLUSIONS}

Vane surface pressure measurements showed good agreement with predictions for a range of Reynolds and Mach numbers. Aerodynamic loss measurenen ts showed a minimum loss at an intermediate Reynolds number for low turbulence. This occurred at all four exit Mach numbers. With a grid installed the loss level at each Mach number was fairly constant. The small grid, with a moderate turbulence lev el, affected the losses almost to the same degree as the large grid, which had a high turbulence level. 
The predictions using the Navier-Stokes code RVC Q:3D are in reasonably good agreement with the data. At low Reynolds numbers, for either low or high inlet turbulence intensity, the andy lys overpredicts losses. The analysis shows increased loss with decreased Reynolds number prior to transition. However, close to the region of minimum loss, presumahly just prior to transition, the analysis overpredicts losses. These are two areas where improvements in flow modeling should result in better agreement with data.

Upstream turbulence in tensity measuremen ts showed good pitchwise uniformity when air was blown counter to the mainstream flow. The grid of large diameter tubes showed high turbulence intensity levels with or without grid air. 'The grid of small diameter tubes had a lower turbulence level with or without grid air. However. in contrast with the large tube grid the turbulence intensity was higher with air blown through the grid. The no grid turbulence intensity was approximately $0.7 \%$

When the upstrean turbulence $w$ as approximately $16 \%$, the downstream midpassage turbulence $w$ as between 2 and $3 \%$. These results are consistent with the Steelant and Dick model for the variation of turbulence with freestrean velocity variation.

Accounting for Mach number effect when the Knudsen number indicates slip flow conditions results in turbulence intensities consistent with the flow physics. Neglecting these effects resulted in turbulence intensities less than one percent at the vane row exit, when the inlet turbulence was about $16 \%$.

\section{REFERENCES}

1. Arts, T., Lambert de Rouvroit, M., and Rutherford, A.W., 1990, "Aero-Thermal Investigation of a Highly loaded Transonic Linear Turbine Guide Vane Cascade." VhI Trehnical Note 174.

2. Price. J.. Jimenez, O.. Miriyala, N., Kimmel, J.B., Leroux, D.R.. and Fahme. 'T'., 2001, "Ceramic Stationary Gas Turbine Development Program - Eighth Anmual Summary." ASME paper 2001-GT-0517.

3. Ames. Forrest E, 1994, "Experimental Study of Vane Heat Transfer and Aerodynamics at Elevated Levels of Turbulence," NASA CR 4633.

4. Boyle. R.J., Lucci, B.L., Verhoff, V.G., Camperchioli, W.P., and La, H.. 1998, "Aerodynamics of a Transitioning Turbine Stator Over a Range of Reynolds Numbers," ASME, paper $98-\mathrm{GT}-285$.

5. Schwab, J.R., 1982, "Aerodynamic Performance of High Turning Core Turbine Vanes in a Two-Dimensional Cascade," NASA TM 82894.

6. Chima, R.V., 1987 "Explicit Multigrid Algorithm for Quasi-Three- Dimensional Flows in Turbomachinery." AIAA Journal of Propulsion and Power, Vol. 3, No. 5. pp. $397-405$.

7. Chima, R.Y., and Yokota, J.W., 1990, "Numerical Analysis of Three-Dimensional Viscous Internal Flows," AlAA Journal, Vol. 28, No. 5, pp. 798-806.
8. Armone, A., Liou, M.-S., and Povinelli, L.A., 1992, "Navier-Stokes Solution of Transonic Cascade Flows Ising Non-Periodic C-Type Grids," AIAA Journal of Propulsion and Pouer, Vol. 8. No. 2. pp. 410-417.

9. Sorenson, R.L., 1980, "A Computer Program to Generate Two-IDimensional Grids About Airfoils and Other Shapes by the l'se of Poisson's Fquation." NASA TM 81198.

10. Boyle, R.I., 1991, "Navier-Stokes Analysis of 'Turbine. Blade Heat Transfer." ASME Journal of Turbomarhinery, Vol. 113, pp. 39:-403.

11. Boyle, R.J., and Ameri, A..A., 1997, "Grid Orthogonality Effects on Predicted Turbine Midspan Heat Transfer and Performance." ASME Journal of Turbomachinery. Vol. 119. pp. 31-38.

12. Boyle. R.I, and Simon, F.F. 1999, "Mach Number Effects on Turbine Blade Transition Length Prediction," ASME Journal of Turbomachinery. Vol. 121. pp. 694-702. 13. Behrens, W., 1971, "Total Temperature Thermocouple Probe Based on Recovery Temperature of a Circular Cylinder," Int. I. Heat Mass Transfer, Vol. 14, pp 1621-1630.

14. Sandhorn. V.A.. 1972, "Resistance Temperature Transducers." Metrology Press, Fort Collins, ( $O$.

15. Barre, S., Dupont. P., and Dussage. J.P., 1992 "Hotwire Measurements in Turbulent Transonic Flows," European Journal of Mechanics, B/Fluids, Vol. 11, pp 439-454. 16. Bruun. H.H., 1995, "Hot-Wire Anemometry-Principles and Signal Analysis," Oxford University Press, New York. 17. Markovin, M.V., 1962. "Effects of Compressibility on Turbulent Flows," Int. Symposium on the Mechanics of Turbulence, CNRS, Paris, France

18. Horstman, C.C', and Rose, W.C., 1977, "Hot-Wire Anemometry in Transonic Flow," AIAA Journal Vol. 15 pp. 395-401.

19. Steelant, J. and Dick, E., 1999 "Prediction of By-Pass Transition By Means of a 'Turbulence Weighting Factor Part I: Theory and Validation," ASME paper 99-('T'-29.

Appendix A - Vane coordinates, cm

\begin{tabular}{|c|c|c|c|c|c|}
\hline CTRUE & GLOWER & Geper & ('TRLE & YIOWEN & $Y_{\text {IIPPEH }}$ \\
\hline 0.000 & 0.742 & 0.742 & 5.5 .37 & 0.855 & 1.651 \\
\hline 0.291 & 0.15 .3 & 1.550 & 5.829 & $0.82 x$ & 1.580 \\
\hline 0.58 .3 & 0.017 & 1.779 & 6.120 & 0.796 & 1.508 \\
\hline 0.874 & 0.012 & 1.922 & 6.411 & 0.758 & 1.432 \\
\hline 1.166 & 0.130 & 2.018 & 6.703 & 0.717 & 1.355 \\
\hline 1.457 & 0.281 & $2.07 !$ & 6.994 & 0.670 & 1.275 \\
\hline 1.749 & 0.412 & 2.117 & 7.286 & 0.619 & 1.193 \\
\hline 2.040 & 0.526 & 2.135 & $7.5 \pi i$ & 0.565 & 1.110 \\
\hline 2.331 & 0.622 & 2.139 & T.869 & 0.500 & 1.024 \\
\hline 2.623 & 0.701 & 2.129 & 8.160 & 0.449 & 0.937 \\
\hline 2.914 & 0.765 & $2.10 x$ & 8.451 & 0.385 & 0.848 \\
\hline 3.206 & 0.815 & 2.079 & 8.743 & 0.319 & 0.758 \\
\hline 3.497 & 0.852 & 2.043 & 9.034 & 0.252 & 0.666 \\
\hline 3.789 & 0.879 & 1.999 & 9.326 & 0.185 & 0.574 \\
\hline 4.080 & 0.895 & 1.951 & 9.617 & 0.121 & 0.479 \\
\hline 4.371 & 0.902 & 1.899 & 9.909 & 0.061 & 0.383 \\
\hline 4.663 & 0.902 & 1.842 & 10.200 & 0.009 & 0.287 \\
\hline 4.954 & 0.893 & 1.784 & 10.395 & 0.128 & 0.128 \\
\hline 5.246 & 0.877 & 1.718 & & & \\
\hline
\end{tabular}


Public reporting burden for this collection of information is estimated to average 1 hour per response, including the time for reviewing instructions, searching existing data sources gathering and maintaining the data needed, and completing and reviewing the collection of information. Send comments regarding this burden estimate or any other aspect of this collection of information, including suggestions for reducing this burden, to Washington Headquarters Services, Directorate for Intormation Operations and Reports, 1215 Jefferson Davis Highway, Suite 1204, Artington, VA 22202-4302, and to the Office of Management and Budget, Paperwork Reduction Project (0704-0188), Washington, DC 20503.

\begin{tabular}{|l|l|l|} 
1. AGENCY USE ONLY (Leave blank) & $\begin{array}{c}\text { 2. REPOAT DATE } \\
\text { November } 2002\end{array}$ & $\begin{array}{r}\text { 3. REPORT TYPE AND DATES COVERED } \\
\text { Technical Memorandum }\end{array}$ \\
\hline
\end{tabular}

\section{TITLE AND SUBTITLE}

5. FUNDING NUMBERS

Aerodynamic Performance and Turbulence Measurements in a

Turbine Vane Cascade

6. AUTHOR(S)

WU-708-28-13-00

Robert J. Boyle, Barbara L. Lucci, and Richard G. Senyitko

7. PERFORMING ORGANIZATION NAME(S) AND ADDRESS(ES)

8. PERFORMING ORGANIZATION REPORT NUMBER

National Aeronautics and Space Administration

John H. Glenn Research Center at Lewis Field

Cleveland, Ohio 44135-3191

E-13457

9. SPONSORINGMONITORING AGENCY NAME(S) AND ADDRESS(ES)

10. SPONSORING/MONITORING AGENCY REPORT NUMBER

National Aeronautics and Space Administration

Washington, DC 20546-0001

NASA TM-2002-211709

GT-2002-30434

\section{SUPPLEMENTARY NOTES}

Prepared for the Turbo Expo 2002 cosponsored by the American Society of Mechanical Engineers and the International Gas Turbine Institute, Amsterdam. The Netherlands, June 3-6, 2002. Robert J. Boyle and Barbara L. Lucci, NASA Glenn Research Center; Richard G. Senyitko, QSS Group, Inc., Cleveland, Ohio 44135. Responsible person, Robert J. Boyle, organization code 5820, 216-433-5889.

12a. DISTRIBUTION/AVAILABILITY STATEMENT 12b. DISTRIBUTION CODE

Unclassified - Unlimited

Subject Category: 34

Distribution: Nonstandard

Available electronically at http://gltrs grc,nasa.gov

This publication is available from the NASA Center for AeroSpace Information. 301-621-0390.

13. ABSTRACT (Maximum 200 words)

Turbine vane aerodynamics were measured in a three vane linear cascade. Surface pressures and blade row losses were obtained over a range of Reynolds and Mach numbers for three levels of turbulence. Comparisons are made with predictions using a quasi-3D Navier-Stokes analysis. Turbulence intensity measurements were made upstream and downstream of the vane. The purpose of the downstream measurements was to determine how the turbulence was affected by the strong contraction through $75^{\circ}$ of turning.

\section{SUBJECT TERMS}

Turbine aerodynamics; Turbulence intensity 15. NUMBER OF PAGES 16. PAICE CODE

\begin{tabular}{|c|c|}
\hline $\begin{array}{c}\text { 17. SECURITY CLASSIFICATION } \\
\text { OF REPORT }\end{array}$ & $\begin{array}{c}\text { 18. SECURITY CLASSIFICATION } \\
\text { OF THIS PAGE } \\
\text { Unclassified }\end{array}$ \\
Unclassified
\end{tabular}
19. SECURITY CLASSIFICATION OF ABSTRACT Unclassified




. 